\title{
Thermal energy storage in the form of heat or cold with using of the PCM-based accumulation panels
}

\author{
Jan Skovajsa ${ }^{1, a}$, Martin Koláček ${ }^{1}$ and Martin Zálešák ${ }^{1}$ \\ ${ }^{1}$ Tomas Bata University in Zlin, Faculty of Applied Informatics, Department of Automation and Control Engineering, Nad Stranemi 4511, \\ Zlin, Czech Republic
}

\begin{abstract}
This article describes the usage of thermal energy storage in the form of heat and cold with an adaptation of the special device which is composed of the thermal panels. These panels are based on the phase change materials (PCM) for normal inner environment temperature in buildings. The energy for the thermal energy storage is possible to get from built-in electric heating foil or from the tube heat exchanger, which is build in the thermal panels. This technology is able to use renewable energy sources, for example, solar thermal collectors and air-to-water heat pump as a source of heat for heating of the hot water tank. In the cooling mode, there is able to use the heat pump or photovoltaics panels in combination with thermoelectric coolers for cooling.
\end{abstract}

\section{Introduction}

One of the biggest disadvantages of modern lightweight structures is the lack of thermal mass. It may cause overheating in the summer or problems with keeping the heat in the winter. This problem can be solved by using $\mathrm{f}$ the thermal energy storage, which can be defined as the temporary storage of thermal energy. It is the accumulation of heat in the materials, specifically in the building structures. [1] These structures transferring their heat to the surrounding when the ambient air temperature drops. During the planning of a building can be minimized the use of cooling devices or even avoid them, mainly due to good thermal accumulation parameters of construction materials.

Thermal energy can be accumulated as sensible or latent heat. Both are not special forms of energy. They describe exchanges of heat in terms of their effect on a material or a thermodynamic system. Sensible heat is heat exchanged by a thermodynamic system that changes the temperature of the system without changing some variables such as volume or pressure. The sensible heat possessed by an object is evidenced by its temperature. Latent heat is associated with changes of state, measured at almost constant temperature. PCMs use a combination of sensible and latent heat.

The main parameter of the accumulation of sensible heat is the specific heat capacity. This parameter determines an amount of energy needed to change the temperature of $1 \mathrm{~kg}$ of the substance by $1 \mathrm{~K}$. The amount of sensible heat energy is calculated from the equation (1).

$$
Q=m \cdot \int_{T_{\mathrm{f}}}^{T_{\mathrm{i}}} c_{p} \mathrm{~d} T
$$

\footnotetext{
${ }^{\mathrm{a}}$ Corresponding author: jskovajsa@fai.utb.cz
}

Where $\quad m$ is mass $[\mathrm{kg}]$

$T_{\mathrm{i}} \quad$ initial temperature $[\mathrm{K}]$

$T_{\mathrm{f}} \quad$ final temperature $[\mathrm{K}]$

$c_{\mathrm{p}} \quad$ specific heat capacity $\left[\mathrm{J} \cdot \mathrm{kg}^{-1} \mathrm{~K}^{-1}\right]$

In the case of accumulation of latent heat, latent heat is consumed or released during the phase change of the material. During this phase transition temperature remains almost constant and there is the possibility to store large amounts of energy into the material. However, there may be a slight change in volume. The total amount of stored energy is determined by changes in enthalpy. The amount of energy is determined from the enthalpy value during the phase change, in the solid state and in the liquid state, according to the following equation (2).

$$
\Delta Q=m \cdot \Delta h
$$

Where $\quad m$ is mass $[\mathrm{kg}]$

$$
\Delta h \quad \text { enthalpy change }\left[\mathrm{J} \cdot \mathrm{kg}^{-1}\right]
$$

Figure 1 shows the principle of thermal energy storage in the form of latent and sensible heat in the PCMs.

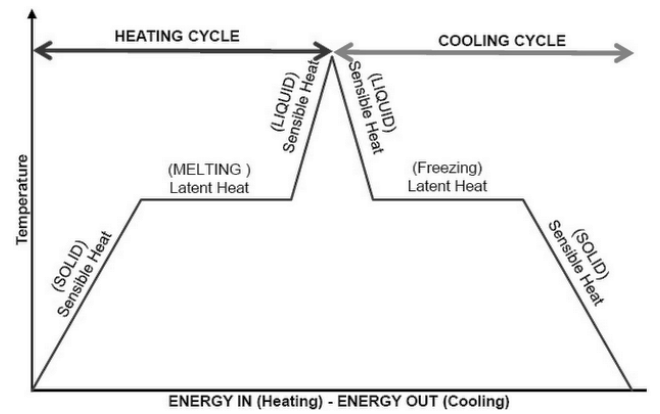

Figure 1. Heating and cooling of PCM. [2] 
Essentially all materials can be considered for PCM. However, the characteristics required for effective and predictable thermal energy storage excludes a large number of materials. Suitable PCMs for households are paraffin, eventually salt hydrates.

Paraffin-based PCMs with a mixture of a polyethylene uses molecular-encapsulation, which is caused by high concentrations of the polymer compound of material. Molecules are designed to that the connection of the individual molecules of the wax creates a homogeneous mixture. Thus formed structure is a highly durable material with a wide operating temperature range from $0{ }^{\circ} \mathrm{C}$ to $40{ }^{\circ} \mathrm{C}$. Molecular-encapsulation also allows drilling and cutting through the material without any PCM leakage. [3]

Today's classic cooling systems are used for room cooling, and these ensure that the rooms are cooled to a comfortable temperature in all environment climates. These systems are effective, but they would have a higher energy efficiency if they used the natural temperature differences between day and night for the purpose of cooling. In these cases, can be applied PCMs that reduce overheating of the room by storing the redundant heat during the day and releasing it during the night. [1]

The PCMs can be used to utilize by natural heat and cold sources, for example, solar energy for heating during the evening and night or the use of night cold for cooling during the day. Furthermore, PCM can use manmade heat or cold sources. In addition, there are different possible uses of the PCMs. In buildings can be placed building structures such as are walls or ceilings, or can be arranged into separate storages of heat or cold. In buildings, the PCMs are often used as passive systems. Using PCMs in separate heat or cold storages are usually based on active systems. Heat or cold is stored in separate storages outside the building and heat or cold transfer is on demand. An interesting option is a technology based on the active system with combination of renewable energy sources. [4]

Nowadays, accumulation of energy in the form of heat or cold is done with large heat storage tanks, or passive accumulation elements, e.g. PCM panels. These commercial PCMs can also be used in active systems, e.g. in ventilation systems, cooling ceilings, cooling beams etc. These active systems are affecting the temperature of the air flow around the element from PCM. It follows that the use of PCM for energy storage is possible and it has already used in some systems, or the new ways of utilization are developed and tested.

The technology, which is proposed in this article is based on commercial PCM panels. The used PCM panels are grouped to one active element including some other technical devices, allowing active management of deliveries of heat or cold, which is obtained from standard external energy sources. The fundamental difference between the standard solutions and proposed technology are the ability to use energy that is gained from any available energy sources including renewable energy sources, e.g. photovoltaics, heat pumps, solar thermal collectors or electrical thermocouples. Another difference is the ability of the active electric cooling, which is not quite common in the PCM devices.

\section{Methods}

\subsection{Technology}

Measurement of parameters was done on the active technology for heating and cooling with the accumulation of heat or cold, which is located in a laboratory at the Faculty of Applied Informatics of Tomas Bata University in Zlín in the Czech Republic. This system is composed of two thermal accumulation panels. Dimensions of one panel are $1.25 \times 0.083 \times 2.07 \mathrm{~m}$ and each of them is composed of 6 layers of PCM panels DuPont Energain. The rear part of panels is insulated and between layers of the PCM panels is imposed copper tube heat exchanger for heating and cooling. The heat exchanger is connected to the water tanks with cold or hot water. There are also imposed three electric heating foils inside the panels.

The mass of thermal panels is composed from mixture of polyethylene and paraffin wax. Paraffin wax is in the solid state at temperatures below $18{ }^{\circ} \mathrm{C}$. When the temperature of panels rises above $18{ }^{\circ} \mathrm{C}$, the wax begin to melt and absorb up to $515 \mathrm{~kJ} \cdot \mathrm{m}^{-2}$ of heat between $18^{\circ} \mathrm{C}$ to $24{ }^{\circ} \mathrm{C}$. Its melting point is about $22^{\circ} \mathrm{C}$, which corresponds to a standard indoor temperature conditions. [4]

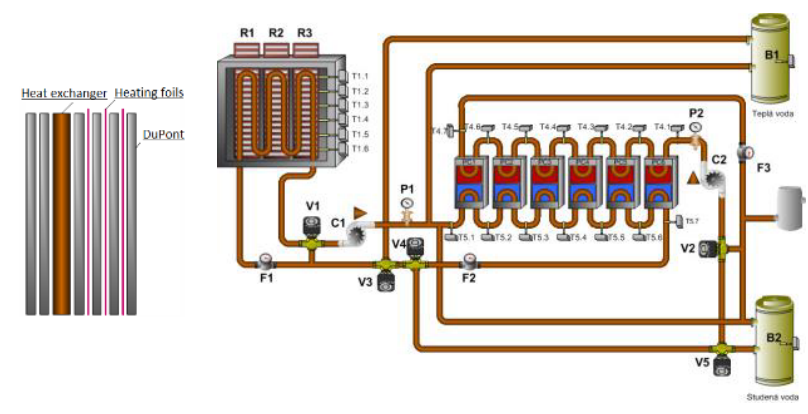

Figure 2. Storage panel and technology scheme. [6]

Figure 2 shows hydraulic connection technology that can use different heat sources, including renewable energy sources. The technology is powered from $230 \mathrm{~V}$ AC power grid and it can also be powered from the photovoltaic system. The photovoltaic system consists of 9 polycrystalline photovoltaic panels with a total area of $11.25 \mathrm{~m}^{2}$. Energy efficiency of a photovoltaic system was set at 11 to $13 \%$ in the earlier measurements.

Technology is further equipped with a thermoelectric coolers which may be powered by photovoltaic panels or from the power grid. Heating of the hot water tank is done by solar thermal collectors or air-to-water heat pump. The heat pump could be also used for cooling of the cold water tank.

\subsection{Operation of technology}

Technology for the accumulation of heat or cold can be operated in different modes which depend on requirements. The technology can be used as a standard passive system. In this mode, technology accumulates heat or cold and for reduction of the temperature peaks and keeps temperature stable in the monitored room during the day and night. The technology can also be operated in 
active mode. In this mode, the technology is able to influence the room temperature by accumulating of the heat or cold which is obtained from external sources. Individual operating modes are described in the following paragraphs of the text.

- Heating of thermal panels by electric heating foils Electric heating foils are installed inside the panel and divided into three sections. Each section has an output of $600 \mathrm{~W}$. Switching of individual sections depends on the temperature of the panel or on the performance of photovoltaics. [6]

- Heating of thermal panels from the hot water tank Inside the thermal panels is tube heat exchanger to transfer heat from the hydraulic part of technology. The hot water tank can be heated by any other installed technology which is available. It is possible to use a heat pump, solar thermal collectors or an electric boiler in this case.

- Cooling of thermal panels from the cold water tank The principle of this mode is similar to the previous mode. This mode also uses a heat exchanger and cold water tank can be cooled by the cooling mode of the heat pump.

- Cooling of thermal panels by thermoelectric coolers Thermocouples are used for the cooling mode. They are able to reach a low temperature but it is necessary to ensure the cooling of their hot sides, because these sides produce large amounts of waste heat. The installed system uses a hydraulic circuit for removing of cold from the thermoelectric elements into thermal panels and a second circuit for waste heat dissipation. The number of switched on elements depends on the amount of supplied energy from photovoltaics. [6]

- Removing of heat or cold from the thermal panels The technology can also be used without active cooling or heating for stored energy in the panels to be transferred into the hot or cold water tank.

\subsection{Measurement}

The aim of the measurement was to determine the changing of the ambient temperature during the heating mode and cooling. There were measured different parameters, but the most important were measurements of temperatures inside the panels, the temperatures of their surfaces, the flow of heat transfer fluid and its temperatures at the inlet and outlet of the exchanger. Furthermore, there was measured the temperature in the room and outdoor temperature by own weather station.

The surface of one panel is painted with black matt paint, see figure 3, which increases the emissivity of the surface and thus also the heat transfer coefficient. Previous research has established the average heat transfer coefficient to a value of $4.1 \mathrm{Wm}^{-2} \mathrm{~K}^{-1}$ for the unmodified surface and $8.3 \mathrm{Wm}^{-2} \mathrm{~K}^{-1}$ for the panel with a modified surface. Another important parameter is the time constant which is around 6.8 hours for the unmodified surface and around 5.5 hours for the modified surface. The time constant of one PCM panel is approximately $75 \mathrm{~min}$. [8]

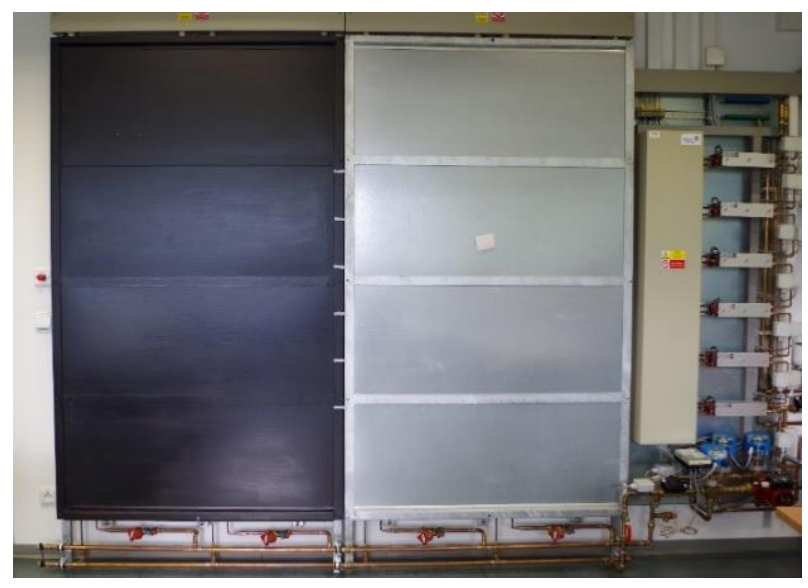

Figure 3. Thermal panels with the original and modified surfaces.

From the measured parameters it was possible to determine the amount of heat or power that was supplied into or removed from the thermal panels by the heat exchanger. The amount of heat and power can be calculated from the equation (1) and the following equation (3).

$$
P=\dot{m} \cdot c_{p} \cdot \Delta \theta
$$

Where $\quad \dot{m}$ is mass flow $\left[\mathrm{kg} \cdot \mathrm{s}^{-1}\right]$

$c_{\mathrm{p}} \quad$ specific heat capacity $\left[\mathrm{J} \cdot \mathrm{kg}^{-1} \mathrm{~K}^{-1}\right]$

$\Delta \theta$ temperature difference $\left[{ }^{\circ} \mathrm{C}, \mathrm{K}\right]$

\section{Results}

Measurement of heating of PCMs has already been examined many times. Another specific utilization is the use of the PCMs in the form of cooling elements. Important parameter of heat accumulation of material is its specific heat capacity. The used PCM has this value around $6800 \mathrm{Jkg}^{-1} \mathrm{~K}^{-1}$ in the temperature range from $10{ }^{\circ} \mathrm{C}$ to $21^{\circ} \mathrm{C}$. The main limiting factor of cooling devices is the risk of condensation of water vapor. So it must be ensured that the surface temperature was at least $1 \mathrm{~K}$ above the dew point temperature.

Figure 4 shows the measurement results of piece of PCM plate which had been cooled to a temperature of $9{ }^{\circ} \mathrm{C}$ in a cooling chamber and then it was placed in a room with an air temperature of $23.5{ }^{\circ} \mathrm{C}$. The test sample had dimensions of $0.5 \times 0.5$ meters and a thickness of $5 \mathrm{~mm}$. The chart shows the behavior of the material, especially in terms of time which is required for reaching room temperature. This material represents nonstandard possibility of using in cooling systems, mainly due to its good parameters. 


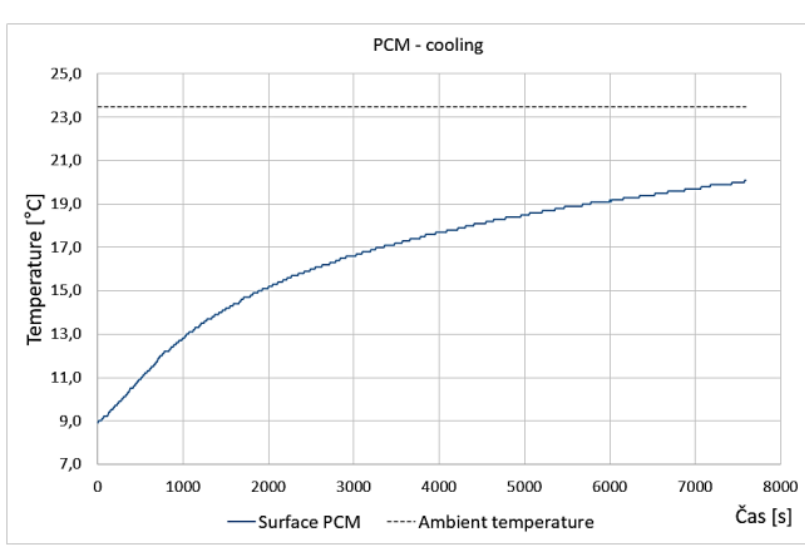

Figure 4. PCM with an initial temperature of $9{ }^{\circ} \mathrm{C}$ placed in a room with a constant temperature of $23.5^{\circ} \mathrm{C}$.

There were been done three different measurements on the technology. The first measurement represents the using of active heating mode, see figure 5. The second measurement represents standard passive mode, see figure 6. The last measurement represents active cooling mode, see figure 7. Heating and cooling of water in water tanks was made by the solar thermal collectors and heat pump.

Active heating mode in figure 5 shows the progress of heating of the thermal panels. At the beginning, it is possible to see that the surface temperature increased slightly, but then the temperature began to rise dramatically. This effect occurred when material has ceased to accumulate latent heat and has started to accumulate only sensible heat. Thermal panels were able to increase the temperature of the air in the room during the day and keep it during the following night. Energy supplied to the panels was $1.9 \mathrm{kWh}$. In passive mode, the thermal panels were able to keep an air temperature steadily, see figure 6 .

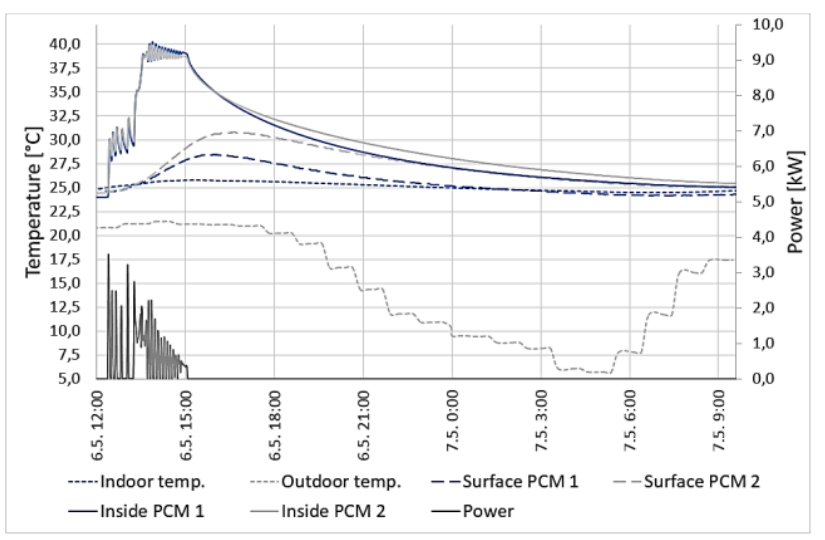

Figure 5. Active mode - heating.

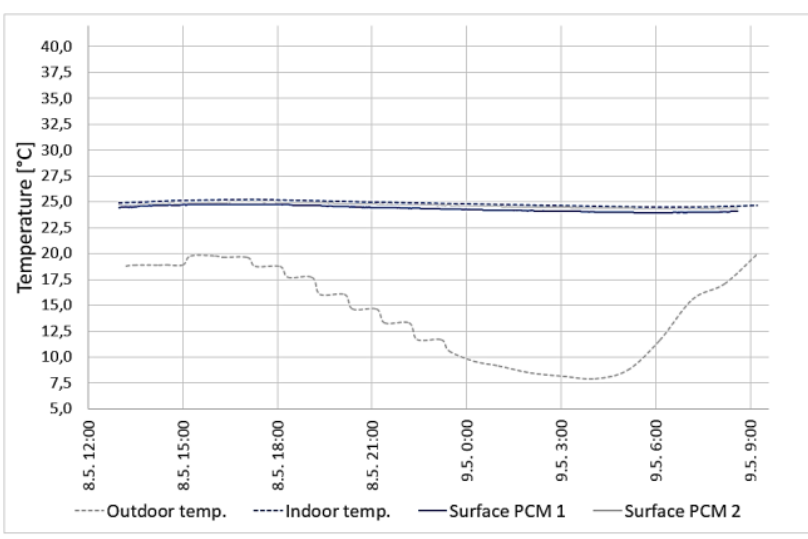

Figure 6. Passive mode.

Active cooling mode in figure 7 shows the progress of cooling of the thermal panels. It is possible to see the effect of surface modification. A time of change of the surface temperatures from $21.2^{\circ} \mathrm{C}$ to $17.7^{\circ} \mathrm{C}$ (unmodified surface) and from $22.4^{\circ} \mathrm{C}$ to $19.8^{\circ} \mathrm{C}$ (modified surface) was around 9 hours. During this cooling, the total amount of energy drained from thermal panels was $3.7 \mathrm{kWh}$. Heating time was approximately 24 hours.

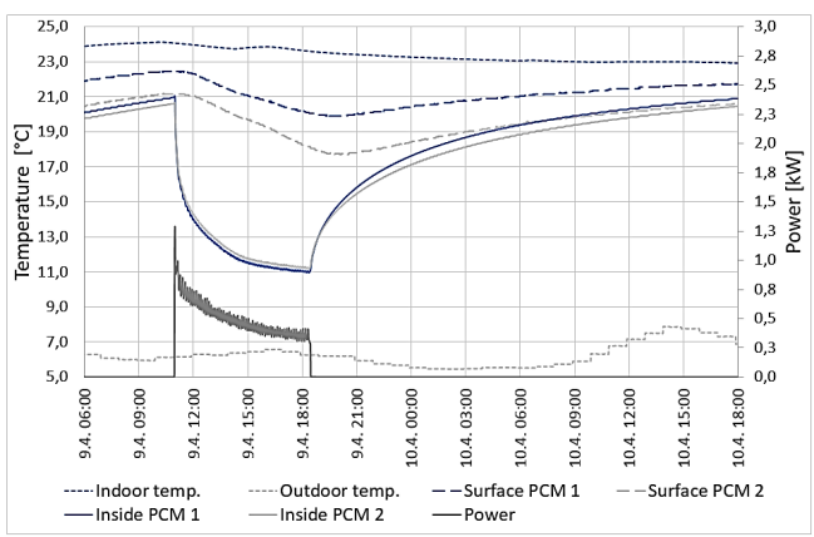

Figure 7. Active mode - cooling.

\section{Conclusion}

The main activity of this research was to measure parameters of the thermal panels based on PCMs.

The advantage of the proposed technology is optimizing parameters of thermal energy storage in buildings and the related achieving better thermal comfort inside the room. Furthermore, there is another advantage, which is the combination of passive and active systems with the use of renewable energy sources. Next advantage is the possibility to control the temperature in the monitored room, but unfortunately, it is possible only in a limited range. This problem is caused by low efficiency at a given size. The problematic factor is a low heat transfer coefficient. Deficiencies can be solved by forced convection and better position of accumulation panels.

The research will continue making changes to convective parameters and using the renewable energy sources. 


\section{Acknowledgement}

This work was supported by the Ministry of Education, Youth and Sports of the Czech Republic within the National Sustainability Programme project No. LO1303 (MSMT-7778/2014) and also by the European Regional Development Fund under the project CEBIA-Tech No. CZ.1.05/2.1.00/03.0089 and also by internal grant agency of Tomas Bata University in Zlin no. IGA/CEBIA$\mathrm{Tech} / 2016 / 001$

\section{References}

1. Joint Implementation Network, Energy Storage: Phase Change Materials for Thermal Energy Storage (ClimateTechWiki, 2010)

2. W. Sutterlin, A brief comparison of ice packs, salts, paraffins and vegetable-derived phase change materials (Plymount: PureTemp, 2014).

3. L. Sánchez, P. Sánchez, A.D. Lucas, M. Carmona, J.F, Colloid Polym Sci, 12, 1377 - 1385 (2007)

4. A. Pasupathy, R. Velraj, R.V. Seeniraj. Renew. Sustainable Energy Rev., 12, 39-64 (2008)

5. Energain ${ }^{\circledR}$ PCM DuPontTM Energain ${ }^{\circledR}$ - A thermal mass solution that's ready to make its mark. (2007)

6. T. Habrovanský, Control and monitoring of heating and cooling units in laboratory of building control systems. (Zlín, 2008)

7. P. Chrobák, S. Sehnálek, M. Zálešák, (Electrorevue, 2014)

8. M. Kolacek, M. Zalesak, IJMR. 3, 7-12 (2016) 